\title{
EDITORIAL
}

\section{REGULACIONES, CONTROLES Y RESPONSABILIDADES}

Los primeros meses del presente año 2008 han estado marcados por una suerte de tensión entre la necesidad de regulación de ciertas actividades, la que no siempre se verifica con la prontitud o en los términos deseados en lo que respecta a la tarea legislativa: el ejercicio de controles por parte de los órganos públicos respecto de las entidades que prestan servicios o que desarrollan tareas relevantes, los cuales no siempre se han delimitado adecuadamente en extensión, precisión de facultades y oportunidad, $y$, finalmente, las responsabilidades que recaen en entidades, instituciones, empresas y personas no solo en referencia al eventual daño que su gestión puede generar, sino especialmente en atención a las legítimas expectativas de los usuarios, del público o la ciudadanía sobre lo que han de reportar estos en diversas áreas.

Estas temáticas, que alguna vez solo se consideraron propias de los órganos públicos y de sus funcionarios o agentes, hoy se transforman cada vez con más fuerza en preocupación tanto del mundo público como del privado. En efecto, la creciente complejización de nuestra época contemporánea, las sinergias, colaboraciones y desarrollos que implican una interacción constante del Estado y de la sociedad civil, la necesidad de recurrir a iniciativas particulares a la vez de fomentos públicos, han hecho cada vez más delgada y más difusa la separación entre estos ámbitos y, por ende, han demandado con mayor fuerza que el establecimiento de regulaciones y controles no haga mayores distingos.

Esta realidad no ha dejado de hacerse presente en el caso chileno y varios de nuestros artículos de este año así lo constatarán: ¿Dónde comienza, pues, el interés o la necesidad de establecer reglas para el lobby?; ¡es preocupación de los entes públicos o de los privados?; ¿quién es el sujeto del daño medioambiental: la comunidad o colectivo, la persona, el Estado?; ¡ es la determinación de ciertas materias de familia un asunto estrictamente "privado"?; ¿las innovaciones tecnológicas son una buena ocasión para la modificación de los estatutos de ciertos servicios o de concesionarias, más allá de las normativas sobre las que establecieron su aporte al país?

No es raro que, en este mismo contexto, el significado mismo de "privacidad", de "servicio" o de "interés público" se transforme lentamente en una materia discutible, ambivalente, lo cual no colabora necesariamente a una mayor riqueza en la discusión jurídica, si no va aparejado de sólidas argumentaciones que puedan enfrentarse en una adecuada competencia de ideas con el norte de una lógica clarificación jurisprudencial, legislativa o doctrinal. Por el contrario, muchas veces presenciamos más bien la renuncia a la unidad y la perniciosa tendencia de dejar que estos conceptos, con los que nos encontramos por cierto en sede civil, constitucional, civil o administrativa, sean finalmente entregados a un intérprete subjetivo y variable, que deconstruya el término según las necesidades puntuales del caso, de la ocasión, incluso del momento político. 
Es indispensable que la comunidad jurídica de nuestro país resista a considerar como aceptable la imposibilidad de definición o la opacidad esencial de la terminología que el propio Derecho utiliza, ya que de otro modo las regulaciones a las que aludimos muy bien pueden transformarse en reglas vacías que solamente son completadas por la voluntariedad de quien las aplica, sin que haya o se pretenda alteridad alguna en ellas; los controles pueden transformarse en armas o herramientas que aludan más bien a una decisión sobre el incentivo o desincentivo de ciertas conductas antes que a su adecuación con principios preexistentes y las responsabilidades podrían quedar sumergidas en el profundo mar de las actitudes benevolentes, de las simpatías o de la reacción que se mide por encuestas más que por resultados objetivos.

En ese contexto, resultan fundamentales las ilustrativas decisiones que, desde sus campos de competencia, están realizando el Tribunal Constitucional, la Contraloría General de la República, las superintendencias, los tribunales, la Cámara de Diputados, cuando ejerce sus funciones fiscalizadoras, y otras tantas entidades preocupadas de dar un semblante de certezas a un país como el nuestro, que muestra importantes índices de desarrollo económico pero que aún se debate en vicisitudes jurídicas largamente superadas en otros ordenamientos.

Todas esas decisiones son ilustradas y acompañadas, innegablemente, por el trabajo constante de nuestros autores, que piensan, debaten y procuran transmitir sus conclusiones para ilustrar y acompañar en el estudio y en la aplicación del Derecho no solo a los particulares interesados en su comprensión, sino también a aquellos encargados de la alta y a la vez azarosa tarea de regular, controlar y hacer valer las responsabilidades que son natural contrapartida de la libertad.

Esperamos, con su participación en las diversas secciones de nuestra Revista, ser un referente del modo en que pueden iluminarse algunas de estas materias y un buen instrumento de consulta para aquellos que resuelven los conflictos en nuestra representación o para aquellos que esperan su resolución con justificada ansiedad, más aún si recordamos que estos últimos no son solo las partes en un juicio o procedimiento, sino, muchas veces, todos nosotros.

ÁngELA ViVANCo MARTíneZ

Directora

Revista Chilena de Derecho 